\title{
Highly efficient resolution of racemic diethanolamine using (-) camphor-10-sulphonic acid
}

\author{
Neelima D. Tangellamudi, ${ }^{a}$ Babu Varghese, ${ }^{b}$ and Govindarajan Sundararajan $*^{a}$ \\ ${ }^{a}$ Department of Chemistry, ${ }^{b}$ Sophisticated Analytical Instruments Facility, \\ Indian Institute of Technology Madras, Chennai-600036, India \\ E-mail: gsundar@iitm.ac.in
}

\begin{abstract}
Dedicated to Professor S. Swaminathan on his $80^{\text {th }}$ birthday
(received 02 Oct 04; accepted 29 Dec 04; published on the web 07 Jan 05)
\end{abstract}

\begin{abstract}
Ring opening of two equivalents of racemic styrene epoxide by benzylamine gives rise to racemic mixture of 2-(benzyl -(2-hydroxy-2-phenylethyl)-amino)-1-phenylethanol, among other diethanolamine products. The racemic mixture is efficiently separated into its enantiomers by complexation with (-) camphor-10-sulphonic acid. The corresponding diastereomeric complex was also characterized by single crystal X-ray diffraction method. This resolution method offers an economically more viable route for the isolation and use of the chiral ligand that has proved to be useful in many asymmetric catalysis reactions.
\end{abstract}

Keywords: 2-(Benzyl-(2-hydroxy-2-phenylethyl)-amino)-1-phenylethanol, camphor-10-sulphonic acid, resolution

\section{Introduction}

According to Eliel, ${ }^{1}$ the most common methods of resolution of chiral compounds can be: i. by mechanical separation of crystals, ii. by formation of diastereomers, iii. by kinetic asymmetric transformation and iv. by biochemical asymmetric transformation. Use of chiral ligands to prepare chiral catalysts is a commonly employed technique for inducing asymmetry in organic reactions. There has of course been a sustained interest in the development and use of enantiomerically pure $\mathrm{C}_{2}$-symmetric ligands as the chiral source to produce products with high enantioselectivity. ${ }^{2}$

In this context, a $\mathrm{C}_{2}$-symmetric chiral ligand, 2-(benzyl-(2-hydroxy-2-phenylethyl)-amino)1-phenylethanol, ${ }^{3} \mathbf{1}$, has acquired meaningful success in asymmetric induction giving appreciable enantioselectivities in various reactions. ${ }^{4}$ In particular, our group has focused on the use of chiral metal complexes derived from this ligand as promoters of asymmetry in many 
organic reactions. ${ }^{5}$ In spite of the apparent simplicity of the chiral precursor viz. styrene epoxide, the commercially available enantiomers are very expensive. ${ }^{6}$ In literature a few resolution methods have been adopted using tartaric acid and dibenzoyl tartaric acid. ${ }^{7}$ Recently a mixture of chiral 1,1'-bi-2-naphthol and inexpensive boric acid in acetonitrile and methanol has also been employed for chiral separation. ${ }^{8}$ We employed all these methods but observed only poor results in terms of enantiomeric excesses and yields.

As part of our continuing program for the development of new methodologies in obtaining enantiomerically enriched diethanolamine, we focused our attention on the utilization of (-) camphor-10-sulphonic acid ((-) CSA). ${ }^{9}$ Herein, we report a highly efficient method for resolution of the racemate using only 0.5 equivalents of (-) CSA, avoiding any recrystallization, to give (-) 1 in $70 \%$ yield with $\geq 99 \%$ ee. We were also able to characterize the intermediate diastereomeric complex of the diethanolamine and CSA by single-crystal XRD techniques lending credence to the suggestion of complex formation in such chiral separations.

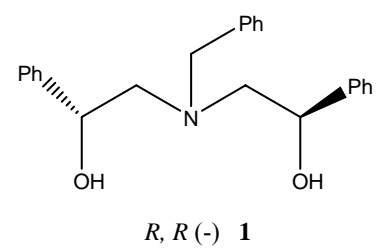

\section{Results and Discussion}

\section{Synthesis of racemic mixture of 1}

The required racemic diethanolamine was synthesized by reacting benzylamine with two equivalents of racemic styrene oxide. The reaction yielded two products containing both the symmetric and the unsymmetric diethanolamines (Scheme 1). The positional isomers 1 and 2 were separated by column chromatography using silica gel. Subsequently the mixture containing both the racemic $(R R, S S)$ and meso $(R S)$ diastereomers of the diethanolamines were separated by preparative HPLC and this racemic mixture of $R, R-\mathbf{1}$ and $S, S-\mathbf{1}$, was subjected to enantiomeric resolution.
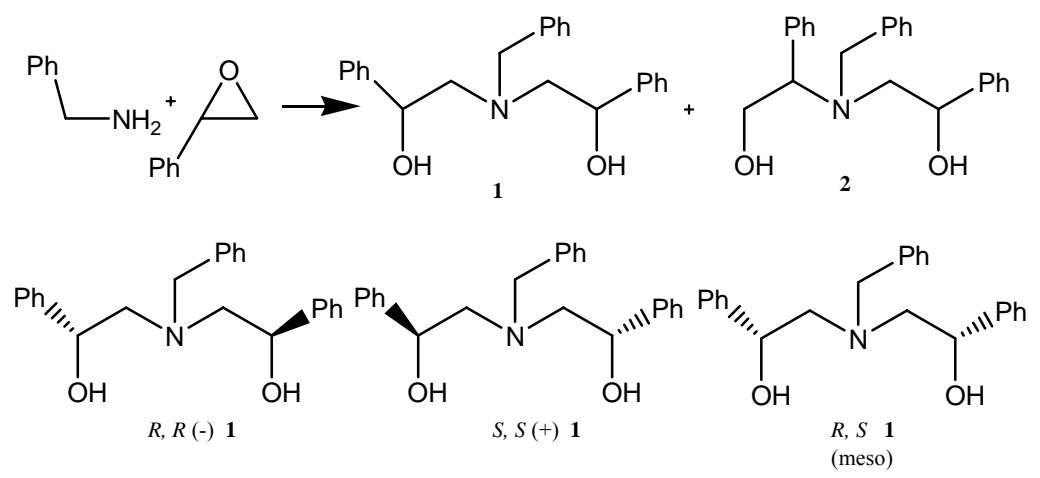

Scheme 1. Diethanolamines from the reaction of styrene epoxide and benzylamine. 


\section{Attempted resolution with diastereomeric copper complexes}

Earlier, in our laboratory, we attempted the resolution of the diethanolamines by forming the corresponding copper complexes and converting the racemate into diastereomers by complexation with D-tartaric acid, D-dibenzoyl tartaric acid and methyl- $\alpha$-D-glucopyranoside. ${ }^{10}$ We anticipated that the high coordinating ability of the metal ion in combination with enantiopure chiral reagent should result in formation of diastereomeric complexes amenable for separation by simple column chromatography. The resolution was carried out by first dissolving the racemic 1 in methanol followed by addition of copper sulphate to form the corresponding copper complex $\mathbf{3}$. The formation of $\mathbf{3}$ was confirmed by mass spectrum of the solid obtained after work up, which gave the expected $\mathrm{M}+$ ion peak. To the methanol solution of the cuprate, tartaric acid or dibenzoyl tartaric acid was added, the reaction mixture was then allowed to settle. The precipitate and the supernatant were separated and purified (Scheme 2). The precipitate was washed with aqueous ammonia and extracted with chloroform. The solution phase was washed with $1 \mathrm{~N}$ hydrochloric acid and extracted with dichloromethane. The resulting isolated diethanolamine showed $2 \%$ ee and $1 \%$ ee from the precipitate and the filtrate respectively as determined both by optical rotation values and chiral HPLC, revealing a poor resolution of the enantiomers by this method.

Resolution was also attempted by adding methyl- $\alpha$-D-glucopyranoside to the racemic diethanolamine cuprate 3 , at $\mathrm{pH}>10$. The solution was mixed and then allowed to settle down, separated and purified (Scheme 2). The precipitate was washed with aqueous ammonia and extracted with chloroform. The solution phase was washed with $1 \mathrm{~N}$ hydrochloric acid and extracted with dichloromethane. The resolved 1 showed $30 \%$ ee with a poor recovery of $10 \%$.

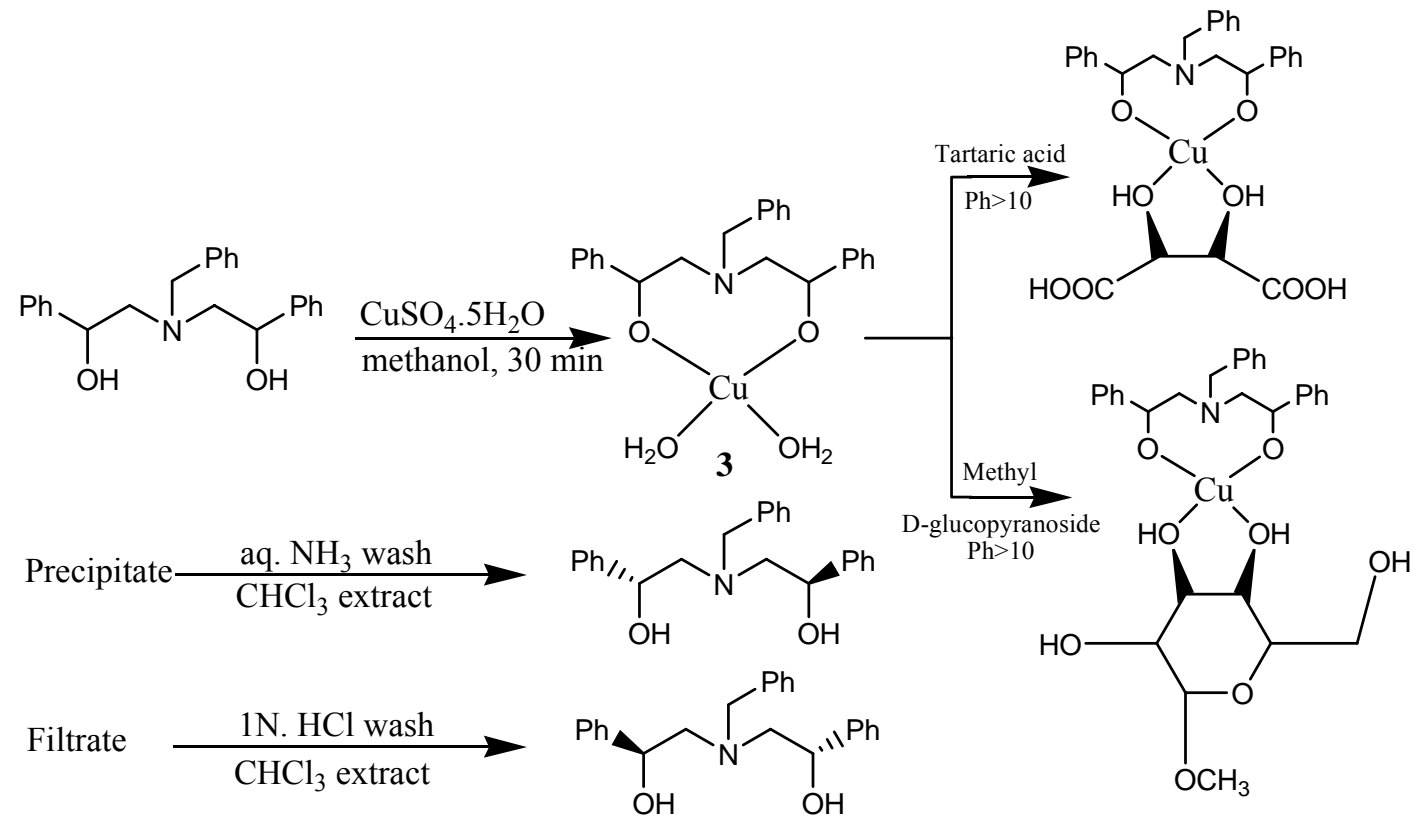

Scheme 2. Attempted resolution of 1 by forming diastereomeric copper complexes. 


\section{Attempted resolution with chiral binaphthol/boric acid mixture}

A mixture of chiral 1,1'-bi-2-naphthol and inexpensive boric acid had proved to be a convenient resolving agent for various racemic aminoalcohols. ${ }^{8}$ We employed the same technique, to resolve the racemic diethenolamine, in our laboratory. It was expected that the reaction of racemic 1, $S(-)$ binol and boric acid in methanol might lead to the formation of the corresponding diastereomeric complex 4, that could be easily separable (Scheme 3). The precipitate and the filtrate after treatment with dilute $\mathrm{HCl}$ followed by base extraction yielded partially resolved enantiomers of $\mathbf{1}$ in $14 \%$ ee and $12 \%$ ee from the precipitate and filtrate respectively.

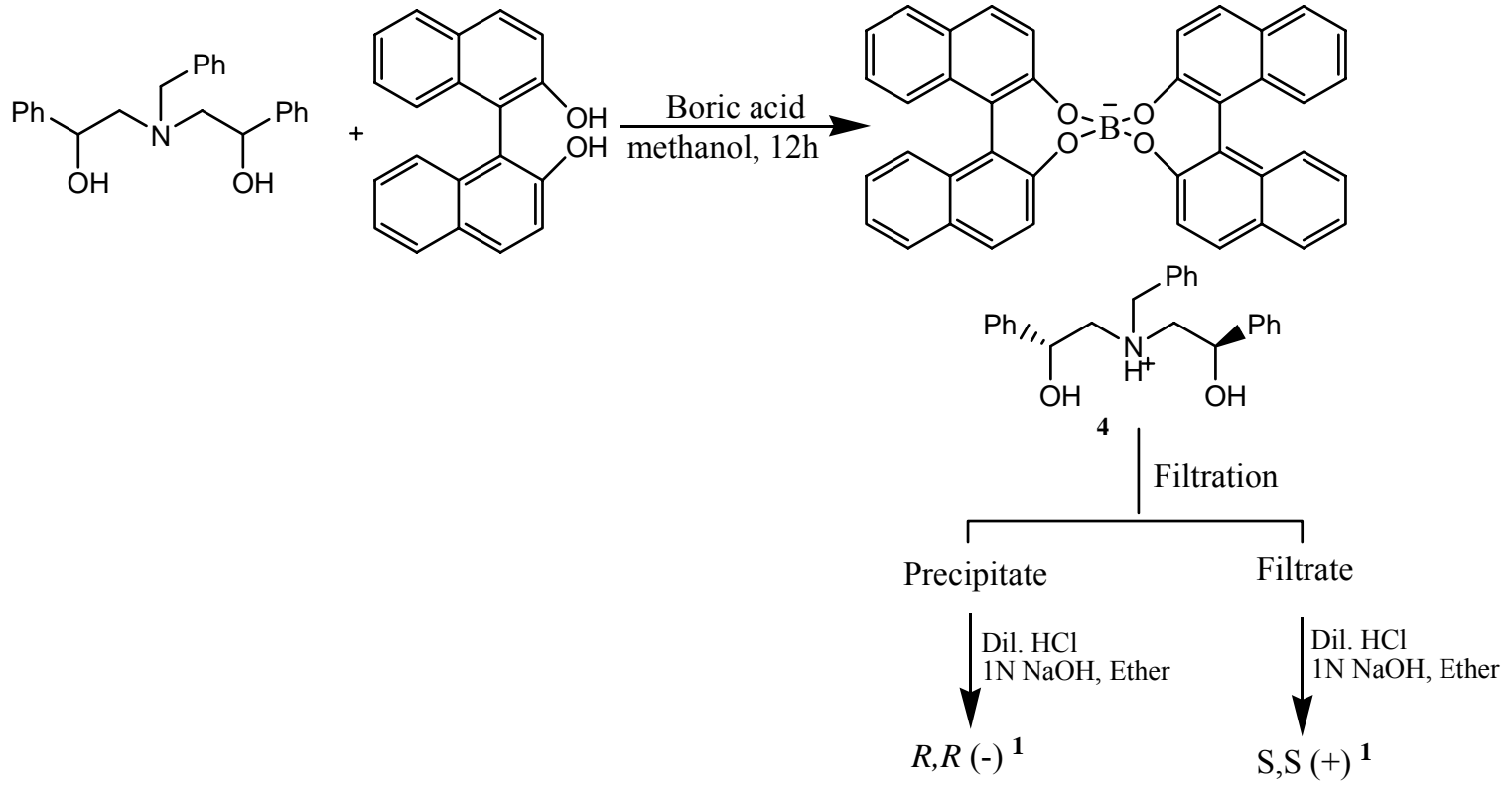

Scheme 3. Attempts at resolving 1 with binol/borate system.

\section{Resolution of the racemic 1 using (-) CSA}

In a separate experiment, we attempted the resolution of racemic 1 with (-) CSA, by dissolving the two compounds in boiling acetone and stirring the mixture at RT for $16 \mathrm{~h}$. The reaction mixture was then allowed to stand and the diastereomeric complex $\mathbf{5}$ precipitated out, which was filtered. The precipitate and filtrate on base extraction yielded $R, R(-) \mathbf{1}$ in $70 \%$ yield with $>99 \%$ ee and $S, S(+) 1$ in $70 \%$ yield with 79\%ee respectively (Scheme 4).

The precipitate obtained also crystallized well in pure acetone at RT and was amenable for unequivocal characterization by single-crystal XRD (Figure 1). The crystallographic data are summarized in Table 1. The prominent hydrogen bonds are summarized in Table 2. The data also helped us to assign the absolute configurations of the chiral centres in the diethanolamine, supported by, of course, the optical rotation values and comparison with the chiral ligands prepared from the commercially available chiral precursors. 


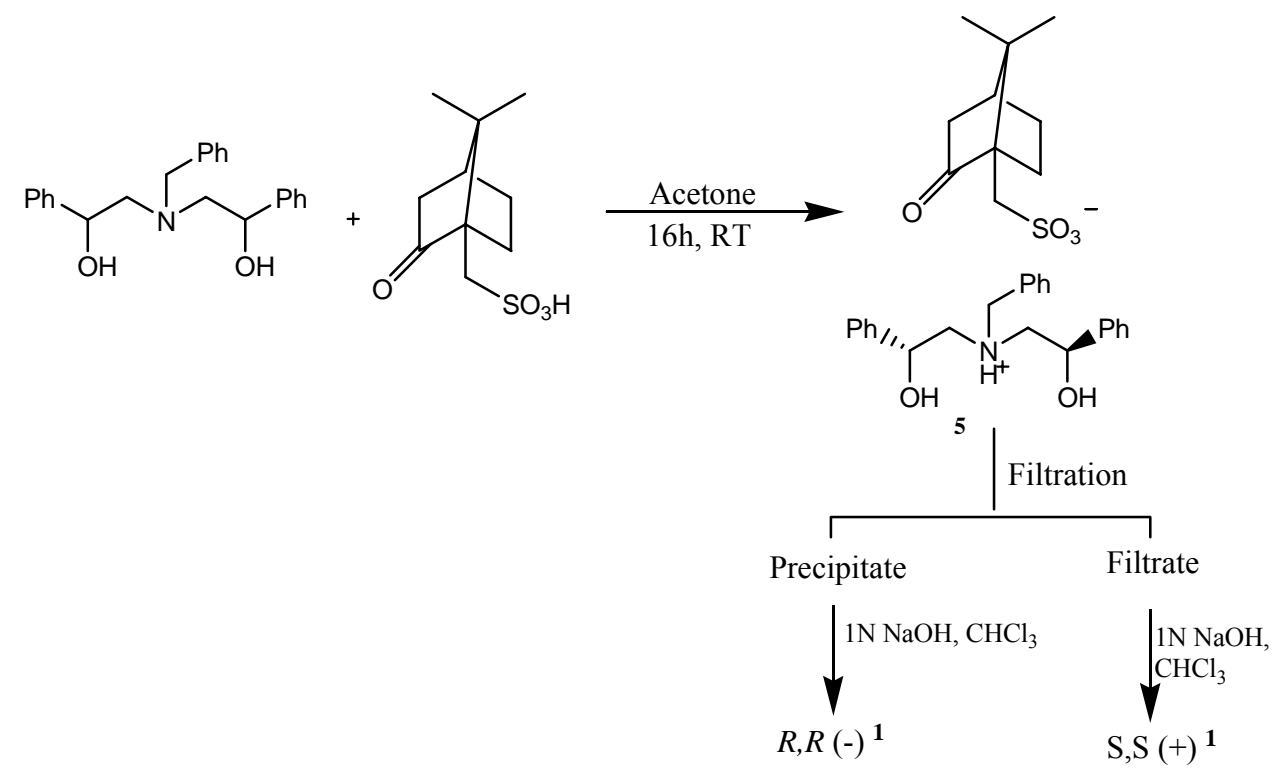

Scheme 4. Enantiomeric resolution of 1 with (-) CSA.

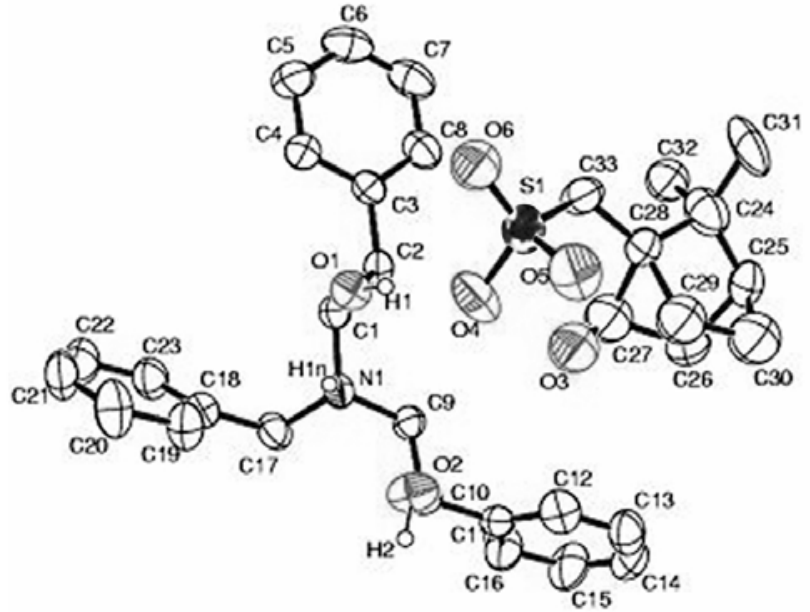

(a)

\begin{tabular}{|l|l|l|l|l|l|l|}
\hline $\begin{array}{l}\text { Donor } \\
\text { (D) }\end{array}$ & $\begin{array}{l}\text { Hydrogen } \\
\text { (H) }\end{array}$ & $\begin{array}{l}\text { Acceptor } \\
\text { (A) }\end{array}$ & $\begin{array}{l}\mathrm{D}-\mathrm{H} \\
\mathrm{A}^{\circ}\end{array}$ & $\begin{array}{l}\mathrm{H}-\mathrm{A} \\
\mathrm{A}^{\circ}\end{array}$ & $\begin{array}{l}\mathrm{D}-\mathrm{A} \\
\mathrm{A}^{\circ}\end{array}$ & $\begin{array}{l}\text { DHA } \\
\circ\end{array}$ \\
\hline $\mathrm{O} 1$ & $\mathrm{H} 1$ & $\mathrm{O} 4$ & 0.82 & 1.89 & $2.697(7)$ & 168.1 \\
\hline $\mathrm{O} 2$ & $\mathrm{H} 2$ & $\mathrm{O} 5$ & 0.82 & 1.87 & $2.671(6)$ & 166.5 \\
\hline $\mathrm{O} 2$ & $\mathrm{H} 2$ & $\mathrm{~S} 1$ & 0.82 & 2.89 & $3.689(4)$ & 164.1 \\
\hline
\end{tabular}

(b)

Figure 1. (a) ORTEP diagram of the complex 5, formed between (-) 1 and (-) CSA (Hydrogen atoms of phenyl and camphor unit are omitted for sake of clarity); (b) Hydrogen bonds for 5.

\section{Enriching $S, S(+) 1$ using (+) CSA}

If $S, S(+)-1$ is the required enantiomer, then the filtrate has to be base treated, worked up, (-) CSA removed and $S, S(+)-1$ is obtained in 79\%ee. The solid is further treated with $(+)$ CSA for enhancement of ee to $>98 \%$ in $70 \%$ yield. The ee of the resolved diethanolamines were measured with HPLC containing chiral column (Figure 2). 

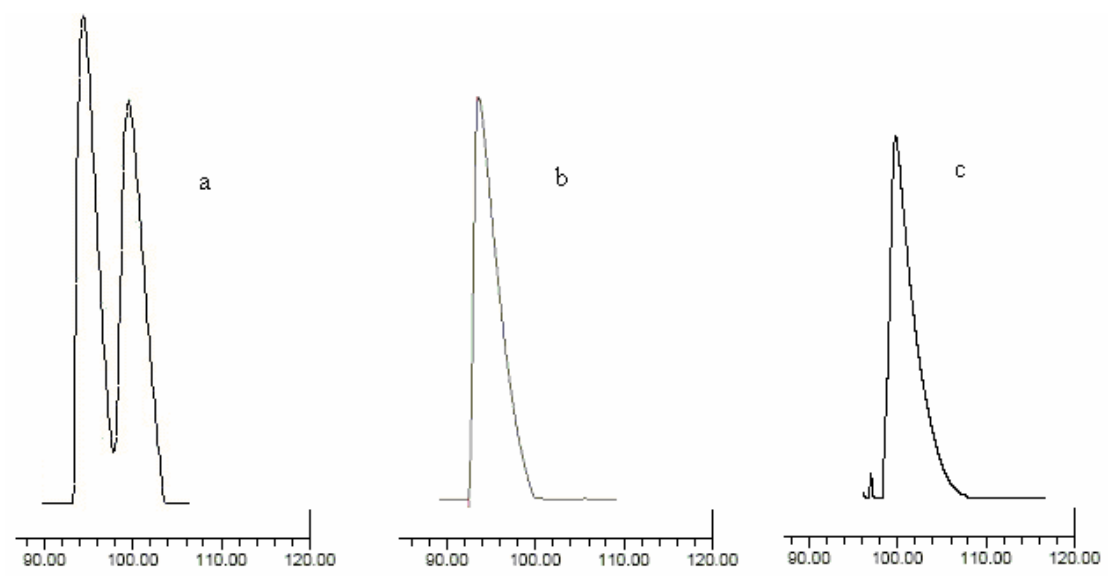

Figure 2. Chiral HPLC traces of 1; (a) resolution of racemic 1 into enantiomers; (b) resolved (-) 1 , ee $=>99 \%$; (c) resolved $(+) 1$, ee $=98 \%$; Column chiralcel ${ }^{\circledR}$ OD; eluant $=$ isopropanol: hexane (2.7:97.3); flow rate $=0.5 \mathrm{~mL} / \mathrm{min}$.

\section{Conclusions}

We have now identified a simple, efficient and convenient procedure for the resolution of racemic diethanolamine to obtain enantiomerically pure compound by complexation with chiral CSA. The intermediate complex was characterized by single-crystal XRD method. We are currently examining the possibilities of resolving other aminoalcohols obtained in the reaction between styrene oxide and amines, which we hope will lead to an interesting source of chiral ligands for further applications in asymmetric catalysis.

\section{Experimental Section}

General Procedures. Racemic styrene oxide, benzylamine and camphor-10-sulphonic acids were purchased and used as such. Waters HPLC with UV detector $(\lambda)$ containing chiralcel ${ }^{\circledR}$ OD column with $0.5 \mathrm{~mL} / \mathrm{min}$ flow rate of isopropanol and hexane (2.7:97.3) was used for estimation of enantiomeric excess of the products. Optical rotations were measured on JASCO DIP-370 polarimeter. X-ray data was collected in ENRAFNONIUS CAD4 diffractometer in the $\omega-2 \theta$ scan mode. ${ }^{1} \mathrm{H}-\mathrm{NMR}(400 \mathrm{MHz})$ and ${ }^{13} \mathrm{C}$-NMR (100.5 MHz) spectra were recorded using BRUKER AV-400 spectrometer.

Synthesis of 1. To a cooled solution of benzylamine $(1.07 \mathrm{~g}, 10.0 \mathrm{mmol})$ in $2 \mathrm{~mL}$ of ethanol, racemic styrene oxide $(2.40 \mathrm{~g}, 20.0 \mathrm{mmol})$ in $4 \mathrm{~mL}$ ethanol was added drop wise at $0^{\circ} \mathrm{C}$ and stirred for $1 \mathrm{~h}$. It was then refluxed for $6 \mathrm{~h}$. After the completion of the reaction, the solvent was removed under reduced pressure to give isomeric diols as a syrupy mass which on flash column chromatography using ethyl acetate: hexane (20:80) as eluant yielded the symmetrical diethanolamines as a colourless oil. 
Separation of racemic and meso isomers of 1 . The racemic and meso diethanolamines in the symmetrical diethanolamine mixture were separated using Shimadzu LC-8A preparative High Performance Liquid Chromatography, containing ODS column. The eluant used was 20:80 (water: methanol) and the flow rate was $10 \mathrm{~mL} / \mathrm{min}$. The observed retention time was $45 \mathrm{~min}$ and 47 min respectively.

Attempted resolution of racemic 1 using tartaric acid. Racemic $1(1 \mathrm{mmol}, 0.347 \mathrm{~g})$ was dissolved in $4 \mathrm{~mL}$ of methanol and $1 \mathrm{mmol}$ of copper sulphate was added and allowed to stir for $30 \mathrm{~min}$. The product obtained was analyzed by Mass Spectrometry and IR spectroscopy. MS $(\mathrm{m} / \mathrm{z}): 410\left(\mathrm{M}^{+}\right)$, 329, 307, 231, 202, 91. IR, $\mathrm{cm}^{-1}$ (neat): 3408, 3232, 1636, 1395, 1136, 1097.

The diethanolamine cuprate complex $(1 \mathrm{mmol}, 0.410 \mathrm{~g})$ was dissolved in $4 \mathrm{~mL}$ of methanol and $1 \mathrm{~N} \mathrm{NaOH}$ was added dropwise to attain a $\mathrm{pH}$ greater than 10 . To this mixture $\mathrm{L}(+)$ tartaric acid $(1 \mathrm{mmol}, 0.15 \mathrm{~g})$ was added and allowed to stir for $30 \mathrm{~min}$. The precipitate obtained on standing was filtered and treated with aqueous ammonia and extracted with $20 \mathrm{~mL}$ of $\mathrm{CHCl}_{3}$. The aqueous layer was treated with $\mathrm{CHCl}_{3}(3 \times 20 \mathrm{~mL})$. The combined organic extracts were washed with saturated brine, dried over anhydrous $\mathrm{MgSO}_{4}$ and evaporated to dryness to obtain $R$, $R(-) 1$ of $2 \%$ ee and with $10 \%$ overall yield $(0.017 \mathrm{~g}) \cdot[\alpha]_{\mathrm{D}}^{25}=-2, c=2.45, \mathrm{CCl}_{4}\left(\mathrm{lit}^{5 \mathrm{a}, 5 \mathrm{e}}:[\alpha]_{\mathrm{D}}^{25}=\right.$ $\left.-131.7, c=2.45, \mathrm{CCl}_{4}\right)$. The filtrate was concentrated and the residue was treated with $1 \mathrm{~N} \mathrm{HCl}$ and extracted with $20 \mathrm{~mL}$ of $\mathrm{CH}_{2} \mathrm{Cl}_{2}$. The aqueous layer was treated with $\mathrm{CH}_{2} \mathrm{Cl}_{2}(3 \times 20 \mathrm{~mL})$. The combined organic extracts were washed with saturated brine, dried over anhydrous $\mathrm{MgSO}_{4}$ and evaporated to dryness to obtain $S, S(+) 1$ of $1 \%$ ee and with $10 \%$ overall yield $(0.017 \mathrm{~g})$. $[\alpha]$ ${ }_{\mathrm{D}}^{25}=+1.1, c=2.45, \mathrm{CCl}_{4}\left(\right.$ lit: $\left.[\alpha]_{\mathrm{D}}^{25}=+131.7, c=2.45, \mathrm{CCl}_{4}\right)$.

Resolution of racemic 1 using (-) CSA. Racemic $1(0.610 \mathrm{~g}, 1.75 \mathrm{mmol})$ and (-) CSA $(0.20 \mathrm{~g}$, $0.85 \mathrm{mmol}$ ) were dissolved in boiling acetone. The mixture was allowed to attain RT and stirred at RT for $16 \mathrm{~h}$. The precipitated obtained on standing, was filtered and treated with $1 \mathrm{~N} \mathrm{NaOH}$ and $20 \mathrm{~mL}$ of $\mathrm{CHCl}_{3}$. The aqueous layer was treated with $\mathrm{CHCl}_{3}(3 \times 20 \mathrm{~mL})$. The combined organic extracts were washed with saturated brine, dried over anhydrous $\mathrm{MgSO}_{4}$ and evaporated to dryness to obtain $R, R(-) \mathbf{1}$ of $\geq 99 \%$ ee and with $70 \%$ overall yield $(0.22 \mathrm{~g})$. $[\alpha]{ }_{\mathrm{D}}^{25}=-129, \mathrm{c}$ $=2.45, \mathrm{CCl}_{4}$ (lit: $\left.[\alpha]_{\mathrm{D}}^{25}=-131.7, c=2.45, \mathrm{CCl}_{4}\right)$. The filtrate was concentrated and the residue was worked up as outlined above to obtain $S, S(+) \mathbf{1}$ of $79 \%$ ee and with $70 \%$ overall yield $(0.21 \mathrm{~g}) .[\alpha]{ }_{\mathrm{D}}^{25}=+90, c=2.45, \mathrm{CCl}_{4}$. The precipitate obtained was also crystallized in pure acetone at RT and characterized by ${ }^{1} \mathrm{H}-\mathrm{NMR}(400 \mathrm{MHz}, \mathrm{DMSO}-\mathrm{d} 6) \delta \mathrm{ppm}: 0.75(\mathrm{~s}, 3 \mathrm{H}), 1.06(\mathrm{~s}$, $3 \mathrm{H}), 1.3(\mathrm{~m}, 2 \mathrm{H}), 1.82(\mathrm{~d}, 2 \mathrm{H}), 1.92(\mathrm{~m}, 1 \mathrm{H}), 2.25(\mathrm{dt}, 4.8$ and $18 \mathrm{~Hz}, 1 \mathrm{H}), 2.70(\mathrm{dt}, 8.0$ and 12.4 $\mathrm{Hz}, 1 \mathrm{H}), \delta 2.41(\mathrm{dd}, 8.0$ and $14.8 \mathrm{~Hz}, 1 \mathrm{H}), \delta 2.92(\mathrm{dd}, 8.0$ and $14.8 \mathrm{~Hz}, 1 \mathrm{H}), \delta 3.28\left(\mathrm{dd}_{\mathrm{ABX}}, 13.80\right.$ and $15.32 \mathrm{~Hz}, 2 \mathrm{H}), 3.42\left(\mathrm{dd}_{\mathrm{ABX}}, 13.51\right.$ and $\left.17.42 \mathrm{~Hz}, 2 \mathrm{H}\right), 4.62(\mathrm{~d}, 14.03 \mathrm{~Hz}, 1 \mathrm{H}), 4.78(\mathrm{~d}, 13.98$ $\mathrm{Hz}, 1 \mathrm{H}), \delta 5.12(\mathrm{br}, \mathrm{OH}, 2 \mathrm{H}), \delta 7.43(\mathrm{~m} .15 \mathrm{H}), \delta 7.91(\mathrm{dd}, 4.11$ and $8.52 \mathrm{~Hz}, 2 \mathrm{H}), 8.98(\mathrm{br}, \mathrm{NH}$, 1H). ${ }^{13} \mathrm{C}$ - NMR (400MHz, DMSO-d6): $\delta 19.8,19.8,27.03,29.68,42.64,42.98,47.43,48.13$, $58.52,60.35,68.57,107.52,125.87,128.15,128.68,129.39,130.22,131.9,140.29,214.03$. 
Enriching $S, S(+) 1$ using (+) CSA. $S, S(+) 1$ of $79 \%$ ee obtained from the filtrate $(0.990 \mathrm{~g}, 2.85$ $\mathrm{mmol})$ and $(+)$ CSA $(0.596 \mathrm{~g}, 0.2 .57 \mathrm{mmol})$ were dissolved in boiling acetone. The mixture was allowed to attain RT and stirred at RT for $16 \mathrm{~h}$. The precipitate obtained on standing, was filtered and worked up as outlined above to obtain $S, S(+) \mathbf{1}$ was of $\geq 99 \%$ ee and with $70 \%$ overall yield $(0.320 \mathrm{~g}) .[\alpha]_{\mathrm{D}}^{25}=+129, c=2.45, \mathrm{CCl}_{4}\left(\right.$ lit: $\left.[\alpha]_{\mathrm{D}}^{25}=+131.7, c=2.45, \mathrm{CCl}_{4}\right)$.

X-ray Crystallographic data collection and refinement of structure. Suitable crystal for single crystal XRD of the diastereomeric complex 5 was obtained from acetone. The crystal of approximate size $0.3 \times 0.3 \times 0.25 \mathrm{~mm}^{3}$ was mounted on a glass fibre. The crystal orientation matrix and the unit cell parameters 5 were derived from a least-squares fit to the goniometer settings of accurately located 25 reflections in the $\theta$ range of $9.88-11.878$ using four-circle Enraf-Nonius CAD4 diffractometer fitted with a graphite monochromated Mo K $\alpha$ radiation. The intensity data collected in the $\theta$ range $1-25^{\circ}$ were corrected for Lorentz, polarization and absorption effects. The structure was solved and refined using SHELX programs.

Crystallographic data for 5. Formula: $\mathrm{C}_{33} \mathrm{H}_{41} \mathrm{NO}_{6} \mathrm{~S}, \mathrm{~F}_{\mathrm{w}}: 579.73, \mathrm{~T}: 293^{\circ} \mathrm{K}$, crystal system: orthorhombic, space group: P212121, $a=10.161(3) \AA, b=12.4349(14) \AA, c=24.164(4) \AA, \alpha=$ $90^{\circ}, \beta=90^{\circ}, \gamma=90^{\circ}, \mathrm{V}=3053.1(12) \mathrm{A} 3, \mathrm{Z}=4, \rho=1.261 \mathrm{Mg} \mathrm{m}^{-3}, \mu=1.305 \mathrm{Mm}^{-1}$, crystal size $=0.3$ x 0.2 x $0.2 \mathrm{~mm}, \theta$ range $=3.66$ to $66.97^{\circ}$, reflections collected $=3078$, no. of unique data $=3078$, $\mathrm{R}$ (int) $=0.0000$, completeness to $\theta=66.97$, maximum and minimum transmission $=0.9989$ and 0.8428 , refinement method $=$ full-matrix least-squares on $\mathrm{F}^{2}$, no. of restraints $=2$, no. of parameters $=412$, goodness-of-fit $=1.036$ on $\mathrm{F}^{2}$, final $\mathrm{R}$ indices $[\mathrm{I}>2 \operatorname{sigma}(\mathrm{I})] \mathrm{R} 1=0.0643, \mathrm{wR} 2$ $=0.1824, \mathrm{R}$ indices (all data) $\mathrm{R} 1=0.0787, \mathrm{wR} 2=0.1996$, extinction coefficient $=0.0034(6)$, largest diff. peak $=0.595$ e. $\AA^{-3}$ and hole $=-0.230$ e. $\AA^{-3}$

\section{Supplementary Information}

The X-ray structure data and ORTEP diagrams are given. Final atomic coordinates of the diastereomeric complex along with the lists of the anisotropic thermal parameters, hydrogen coordinates, bond lengths and bond angles have been deposited with the Cambridge Crystallographic Data Center, 12 Union Road, Cambridge CB2 1EZ, United Kingdom. Ref: CCDC251198.

\section{Acknowledgements}

We acknowledge CSIR for financial assistance (No: 01/1755/02/EMRI) and IIT Madras for the facilities. We gratefully acknowledge Prof. S. Sankararaman (IITMadras) for his valuable suggestion in this work. 


\section{References and Notes}

1. Eliel, E.L; Wilen, S.H. Stereochemistry of Organic Compounds; Wiley: New York, 1994.

2. (a) Whitesell, J. K. Chem. Rev. 1989, 89,1581. (b) Burk, M.J.; Feaster, J.E.; Harlow, R.L.Tetrahedron: Asymmetry 1991, 2, 569. (c) Evans, D.A.; Nelson, S.C.; Gagne, R.; Muci, A.R. J. Am. Chem. Soc. 1993, 115, 9800. (d) Manickam, G.; Sundararajan, G. Tetrahedron: Asymmetry 1999, 10, 2913. Boulch, R. Scheurer, A.; Mosset, P.; Saalfrank, R.W. Tetrahedron Lett. 2000, 41, 1023. (g) Bolm, C.; Martin, M.; Simic, O.; Verrucci, M. Organic Lett. 2003, 5, 427.

3. (a)Trost, B.M.; Vranken, D. L.V.; Bingel, C. J. Am. Chem Soc. 1992, 114, 9327. (b) Manickam, G.; Sundararajan, G. Indian. J. Chem. 1996, 35B, 1006.

4. (a) Evans, D.A.; Nelson, S.G.; Gagne, M. R.; Muci, A.R. J. Am. Chem. Soc. 1993, 115, 9800.

(b) Dubois, L.; Fiaud, J. -C.; Kagan, H.B. Tetrahedron: Asymmetry 1995, 6, 1097. (c) Dubois, L.; Fiaud, J. -C.; Kagan, H.B. Tetrahedron 1995, 51, 3803. (d) Krohn, K.; Knauer, B.Recueil des Travaux Chimiques des Pays-Bas. 1996, 115, 140. (e) Davies, C.D.; Marsden, S.P.; Stokes, E. S. E. Tetrahedron Lett. 1998, 39, 8513. (f) Aggarwal, V.K.; Mereu, A.; Tarver, G.J.; McCague, R. J. Org. Chem. 1998, 63, 7183. (g) Mikami, K.; Yamaoka, M.; Yoshida, A. Synlett 1998, 607. (h) Farthing, C. N.; Marsden, S.P. Tetrahedron Lett. 2000, 41, 4235.

5. (a) Manickam, G.; Sundararajan, G. Tetrahedron: Asymmetry 1997, 8, 2271. (b) Manickam, G.; Sundararajan, G. Indian J. Chem. 1997, 36A and B, 516. (c) Manickam, G.; Sundararajan, G. Tetrahedron 1999, 55, 2721. (d) Sundararajan, G.; Prabagaran, N. Org. Lett. 2001, 3, 389. (e) Prabagaran, N.; Abraham, S.; Sundararajan, G. Arkivoc 2002, (vii), 212.

6. Year 2004 catalogue of Aldrich Chemical Company quotes a price of $R(+)$-Styrene Oxide at USD 35.50/g and $S$ (-)-Styrene Oxide at USD 38.80.0/g. The cost of the R enantiomer works out to be less than USD $2.50 / \mathrm{g}$ as per the present method.

7. (a) Leigh, T. Chem. Ind. 1977, 1, 36. (b) Law, H.; Leclerc, G. A.; Neumeyer, J. L. Tetrahedron: Asymmetry 1991, 2, 989.

8. (a) Periasamy, M.; Venkatraman, L.; Sivakumar, S.; Kumar, N.S.; Ramanathan, C.R. J. Org. Chem. 1999, 64, 7643. (b) Periasamy, M.; Ramanathan, C.R.; Kumar, N.S. Tetrahedron: Asymmetry 1999, 10, 2307. (c) Periasamy, M.; Kumar, N.S.; Sivakumar, S.; DharmaRao, V.; Ramanathan, C.R.; Venkatraman, L. J. Org. Chem. 2001, 66, 3828.

9. (a) Brandt, J.; Gais, H. Tetrahedron: Asymmetry 1997, 8, 909. (b) Stingl, K; Kottenhahn, M.; Drauz, K. Tetrahedron: Asymmetry 1997, 8, 979.

10. Prabagaran, N. Ph.D thesis. Department of Chemistry. IIT Madras. February 2002. 